\title{
The Benefit Assessment of the Physiotherapy Sessions for Children with Autism Spectrum Disorder
}

\author{
Lina Draudvilienè1, Sergej Sosunkevič², Laura Daniusevičiūtė-Brazaitė ${ }^{1}$, \\ Aušra Burkauskiené ${ }^{3}$, Justas Draudvila ${ }^{4}$ \\ Kaunas University of Technology', Kaunas, Lithuania \\ Kaunas University of Applied Sciences Kauno kolegija², Kaunas, Lithuania \\ Lithuanian University of Health Sciences, Medical Academy ${ }^{3}$, Kaunas, Lithuania \\ Lithuanian Sports University ${ }^{4}$, Kaunas, Lithuania
}

\begin{abstract}
Background. Children with autism disorder show atypical preference for non-social stimuli. Therefore, the deficits of social communication and social interest are primary and usually named features for the Autism Spectrum Disorder (ASD). The main idea of the present work was to show that the physiotherapy sessions (PS) were some of the ways that could improve the physical condition of children with ADS. Moreover, the application of such programs increased self-esteem, communication skills and permitted a better adaptation and integration within society.

Methods. Eleven children attending kindergarten for children with special needs participated in this investigation. The inclusion criteria were a clinical diagnosis of ASD. All participants had F 84.0 code in their cases and were specified for grade II autism disorder according to the American Psychiatric Association (2014). The investigation process consisted of four stages: the initial testing, the application of the physiotherapy program (PS), the postapplication testing and the analysis, interpretation and comparison of obtained results. The investigation process was applied for six weeks.

Results. After PS applications, the children's balance improved by $21.32 \%$, coordination $-23.36 \%$, physical and functional abilities such as speed (13.18\%) and explosive leg strength (37.14\%).

Conclusions. The physiotherapy sessions improved the physical condition of children with ADS: balance, coordination, functional abilities and the explosive leg strength. The capability to do physical exercises in a group, at home or in individual sessions with specialist improved as well.
\end{abstract}

Keywords: pre-school children, individual physiotherapy program, social skills.

\section{INTRODUCTION}

$\mathrm{R}$ ecently the prevalence of ASD has increased rapidly and is growing constantly in the world. According to the World Health Organization (WHO, 2018), an average number of children having an ASD is globally 1 in 160 (Keogh et al., 2019). However, even this number does not reflect the real situation, the prevalence of ASD in many low - and middle-income countries is unknown so far (WHO, 2018). Based on the current statistics of the United States, the prevalence of ASD is estimated to 1 in 40 between 3-17 years old children (Kogan et al., 2018). In Europ, the average estimated prevalence is 1 in 89 between 7-9-yearold children (ASDEU, 2018). Meanwhile, in the early 1970s, children with ASD were calculated in the range of 2 to 4 per 10,000 in Europe and United States (Boat \& Wu, 2015; Ye, Leung, \& Wong, 2017).

The WHO indicates that the prevalence of ASD appears to be increasing over the past 50 years due to a few reasons: improved awareness, expansion of diagnostic criteria, better diagnostic tools and enhanced reporting (WHO, 2018). According to the statistical data provided by Centers for Disease 
Control and Prevention (CDC, 2019), an average of about $1-2 \%$ of the population has been diagnosed with autism (Ye et al., 2017). Therefore, there is no doubt that similar studies in all countries around the world, with timely medical diagnosis, would confirm the prevalence of 2 percent autism syndrome. However, the prevalence of ASD is related not only with better diagnostics. Recently, it has been widely accepted that a combination of genes and environmental factors are the main causes of ASD (David, Babineau, \& Wall, 2016; Modabbernia, Velthorst, \& Reichenberg, 2017; Nevison, 2014; Ye et al., 2017). More than 60 genes are recognised as the source of autism (De Rubeis et al., 2014; Robinson et al., 2016). The heredity gene is named as one of the most influencing which affects approximately 40 percent (Stein, Parikshak, \& Geschwind, 2013). According to recent evidence, the environmental factors have also no less impact and might have an influence on about $40-50 \%$ of ASD cases (Modabbernia et al., 2017). The environmental risk factors such as heavy metals inorganic mercury $(\mathrm{Hg})$ and lead $(\mathrm{Pb})$ (Fujiwara, Morisaki, Honda, Sampei, \& Tani, 2016; Modabbernia et al., 2017; Ye et al., 2017), organic chloride used in agriculture for the prevention and control of pests pesticide (Fujiwara et al., 2016; Modabbernia et al., 2017; Ye et al., 2017) are associated with an increased risk of ASD.

The ASD is assigned to the category of neurodevelopmental disorders leading to abnormal brain function. Therefore, such disorders may affect emotions, learning ability, self-control and memory, along with repetitive patterns or hobbies of stereotypical behaviour and limited interests, which has much influence on social communication (Giannopulu \& Pradel, 2010; Lim et al., 2019; Masi, DeMayo, Glozier, \& Guastella, 2017; Mohajer et al., 2019). This leads to the fact that these children have restricted interests and lack of socio-communicative interaction (Gale, Eikeseth, \& Klintwall, 2019; Lim et al., 2019). According to Gale et al. (2019) and van der Zee and Derksen, (2020), children with autism show atypical preference for non-social stimuli due to their low empathy skills. These deficits of social communication and social interest are usually named as the primary feature of the ASD. At the physical level, such disorder influences human motor skills, coordination, balance, functional ability. In the meantime, motor control and communication have overlapping neural systems, therefore it is stated that the motor development is one of the mechanisms for communication development (Stevenson, Lindley, \& Murlo, 2017). Studies show that autistic children have more impaired motor abilities, such as grabbing, holding, and throwing a ball. Later, these talents improve (McCleery, Elliott, Sampanis, \& Stefanidou, 2013). Also, motor skills are closely linked to daily activities that require coordination between the fingers, hands, hands and vision (Cuffaro, 2011). According to Connolly et al. (2019), Memari et al. (2013), and Miller, Caçola, Sherrod, Patterson, and Bugnariu, (2019), children with ASD are more disturbed in their balance than ordinary children, which results in a higher risk of injuries and in poorer posture. About 80 percent of children with ASD have some visual and motor integration deficiencies, which is captured by the lack of eye-body coordination (Caro, Tentori, Martinez-Garcia, \& Alvelais, 2017). However, atypical social behaviours influence autists' participation in physical activity (PA). Children with ASD are less likely to be active; they are considered to be mainly inactive (Gregor et al., 2018). According to MacDonald, Esposito, and Ulrich's (2011) study, older children with ASD are more physically inactive as younger children. Therefore, older children with ASD are at a higher risk of developing overweight and obesity (Egan, Dreyer, Odar, Beckwith, \& Garrison, 2013; Gregor et al., 2018). In addition, this can lead to type 2 diabetes and cardiac pathologies and exacerbate the physical and mental health of such cases (Williams, Eleftheriadou, Alam, Cuthbertson, \& Wilding, 2019). According to Healy, Aigner, \& Haegele (2018), youth with ASD is one group observed to be of a particularly risk for overweight and obesity (Curtin, Jojic, \& Bandini, 2014). In the U.S in the 2016, the prevalence of overweight is 19 percent and obesity - 23 percent of children with ASD (Healy et al., 2018; Nor, Ghozali, \& Ismail, 2019). Therefore, the emerging research suggests that the PA is important for everyone and has positive effects on physical and mental health (Carson et al., 2013; Gregor et al., 2018).

The growing numbers children with autism are increasing globally and constantly. Zerbo et al. (2019) indicate that overall healthcare services for adult with ASD costs $70 \%$ more than it costs for general population. Similar cost patterns for children and adolescents with ASD are obtained (Zerbo et al., 2019). Therefore, assistance is needed not only in physical rehabilitation skills but also in the improving communication skills, which could 
facilitate future integration which will possibly decrease the overall healthcare services costs.

The aim of the present work is to show that physiotherapy was one of the ways for the children with ADS to improve their physical condition. At the same time application of such programs could help to increase self-esteem, to improve communication skills and faster adaptation and integration into the society.

\section{METHODS}

Participants. Eleven children attending kindergarten for children with special needs participated in this investigation. The inclusion criteria were a clinical diagnosis of ASD. All participants had F 84.0 code in their cases and were specified for grade II autism disorder according to the American Psychiatric Association (2014). Each participant's parents read and signed a written informed consent form consistent with the principles outlined in the Declaration of Helsinki. The main information about physical data of the children (age $5.6 \pm 1.12$ years, weight $23.2 \pm 6.1 \mathrm{~kg}$ and height $117.2 \pm 9.41 \mathrm{~cm}$ ) is presented in Table 1. They all had ASD and attended the same kindergarten. The local bioethics permission was given.

Table 1. Participants' age, height and weight

\begin{tabular}{|c|c|c|}
\hline Years & Height & Weight \\
\hline $\mathbf{4}$ & 100 & 15.5 \\
\hline $\mathbf{4}$ & 104 & 16.6 \\
\hline $\mathbf{5}$ & 109 & 18 \\
\hline $\mathbf{5}$ & 125 & 28.5 \\
\hline $\mathbf{5}$ & 119 & 21 \\
\hline $\mathbf{6}$ & 115 & 19.5 \\
\hline $\mathbf{6}$ & 126 & 25 \\
\hline $\mathbf{6}$ & 122 & 36 \\
\hline $\mathbf{7}$ & 116 & 22 \\
\hline $\mathbf{7}$ & 128 & 25.5 \\
\hline $\mathbf{7}$ & 125 & 28 \\
\hline
\end{tabular}

A new method of PS has been applied to these children, so this group could be named as a pilot group.
Study design and procedure. The observation of autistic children was performed in their natural environment - an indoor gym. Before launching the procedural tests, there was a communication period with every child for about one week. This time was necessary for children to get used to new people and to evaluate each child's understanding capacity: listening and task performance. Then the testing to determine and assess the primary condition of each child was carried out.

The investigation process consisted of four stages. In the first stage, the initial test was conducted to evaluate the children's physical state, capacity, and ability. For that reason, a complex of tests was selected.

Children's balance scale (modified Berg Balance scale). This test is used for elderly people after heart attack and to test children with known balance impairment and it is suitable for children aged 4-12 years (Sibley, Beauchamp, Van Ooteghem, Paterson, \& Wittmeier, 2017). A study of functional skills related to balance assessment consists of a set of 14 tasks with a total duration of 20 minutes. This test is used to determine the functional abilities needed for daily activities related to balance. Balance is determined by changing position and performing various manoeuvring movements at the same time. These tasks are practiced while sitting, standing and with eyes closed. The modified Berg scale involves a 5 -point system ranging from 0 to $4(0-1-2-3-4)$. The maximum number of points that can be collected is 56 points. If the final result of the test is less than 45 points, the person is considered to have serious imbalances, which increases the likelihood of falls (Gan, Tung, Tang, \& Wang, 2008).

Coordination sample not requiring balance. Coordination test consists of a set of 15 tasks. Each task is rated from 0 to 4 points. Scores are awarded according to the scores assigned in the test regulations: 0 points - lack of precise movements and bad posture of the body; 1 point - very difficult to maintain body position, arrhythmic movements, inaccuracy, tremors, side movements; 2 points - much harder to maintain posture, nonrhythmic movements, and more inaccuracy with faster performance; 3 points - slightly more difficult movements or posture, inaccuracies; 4 points - normal static and dynamic body position maintained, movements performed according to all requirements. The maximum assessment of the test is 60 points (O'Sullivan, Schmitz, \& Fulk, 2019). 


\begin{tabular}{|l|l|}
\hline Rubbing feet on the massage machine & 1 min \\
\hline Stable ball grip & 1 min \\
\hline Lying on the back, on a large roller, stretching & 3 min \\
\hline Steps by foot placed on the floor & 4 repetitions \\
\hline Steps by foot placed on the floor turned sideways & 4 repetitions \\
\hline Jump over three obstacles with both feet & 8 repetitions \\
\hline $\begin{array}{l}\text { Throwing a ball, first with a small ball, then a bigger one, if done well, } \\
\text { then it is thrown with one hand }\end{array}$ & $\begin{array}{l}4 \text { repetitions, } \\
10 \text { passes each }\end{array}$ \\
\hline $\begin{array}{l}\text { Jumping by colour with both legs an then one in five coloured arcs } \\
\text { placed on the ground }\end{array}$ & $\begin{array}{l}8 \text { jumps } \\
2 \text { series }\end{array}$ \\
\hline Shuttle running & 1 min, 2 series \\
\hline Standing on an unstable plate & 1 min \\
\hline $\begin{array}{l}\text { Climbing the soft stairs and walking on the bench } \\
\text { Lying on the stomach, on a physiotherapy ball, rolling forward with } \\
\text { the help of hands and going back to lay the knees on the ground }\end{array}$ & 2 min \\
\hline haising the medical ball above the head and lowering it to the & $\begin{array}{l}5 \text { repetitions, } \\
2 \text { series }\end{array}$ \\
\hline $\begin{array}{l}\text { Opposite arm and leg reach } \\
\text { hands while exhaling through the mouth. }\end{array}$ \\
\hline
\end{tabular}

Eurofit Fitness Test Battery. Assessment of physical and functional abilities. According to Latorre Román et al. (2015), the Fitness Test Battery is valid and reliable for the evaluation of the pre-school children's physical fitness. Therefore, the motor abilities were assessed by physical fitness tests adapted from EUROFIT test batteries (Metwaly, 2015). Two tests are selected that relate to different components of physical performance and describe different attributes of performance. One of the tests is the $10 \times 5 \mathrm{~m}$ shooting range; the physical component is speed and shows the child's agility. Another test is the jump from the place. The component of physical capacity is force and shows the child's explosive strength. For the first test, the shuttle running time is recorded by a stopwatch and then converted to a numerical estimate, for example: $21.6 \mathrm{~s}=216$. In the second test, the distance of the long jump is measured with a centimetre strip and converted to a numerical estimate, for example: jump $1 \mathrm{~m} 56$ $\mathrm{cm}$ - result 156 .
During the testing time the children were evaluated on communication, understanding and listening. Such skills are very important for the future PS application and interpersonal communication.

The second stage was the application of the Physiotherapy program. Summarizing the initial testing results, the PS was developed for all children. The program consisted of physical exercises and presented in Table 2.

The third stage involved the post-application testing. After six weeks of PS application, the postapplication testing using the same tests as in the first stage was performed. Aiming at evaluating how the PS program influenced the children's physical condition, the same pre-tests were used.

The fourth stage was the analysis, interpretation and comparison of the obtained results. The investigation process is presented in Figure.

The Windows software SPSS 19.0 was used for statistical analysis of the obtained results This program was used to calculate results, significance and standard deviation. 
Figure. The scheme of the investigation process applied individually for each participant

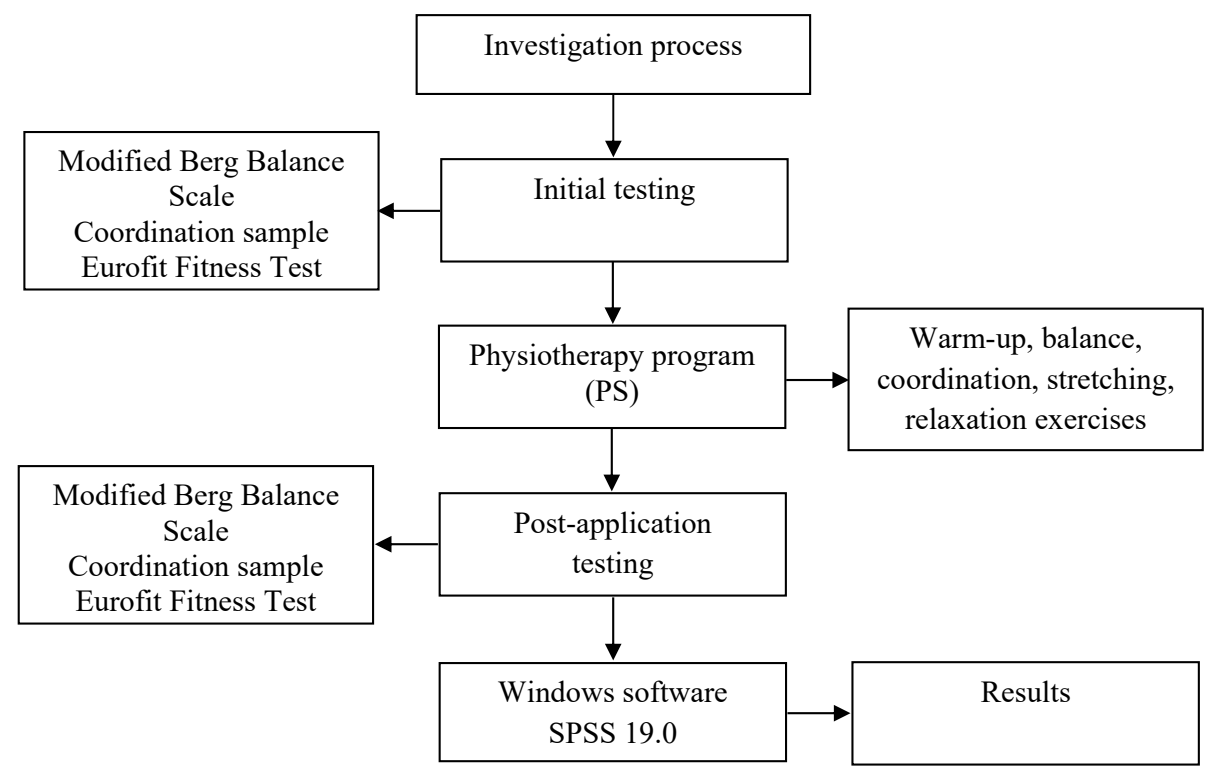

\section{RESULTS}

The obtained results are presented in Table 3 . The efficiency is expressed as a percentage for the better comparison.

The analysis showed the overall outcome improvement. For instance, for the Modified Berg functional balance scale, the average score collected by children before physical therapy was $\sim 36.91 \pm$ 7 (Table 3) out of 56 possible, which means they had a significantly disturbed balance. After the PS, the average score of the Modified Berg balance scale increased to $\sim 46.91 \pm 6.9$, which could be attributed to a slight imbalance. The application of the PS exercises improved the balance outcome by $21.32 \%$ (Table. 3 ).

The coordination sample had a mean score of $\sim 31.55 \pm 16.55$ (Table 3) out of 60 possible scores. This is a real inadequate result and means that for children it is much harder to maintain posture; movements are not rhythmic and become even more inaccurate with increasing performance speed. Meanwhile, the average of the results after PS application was $\sim 41.18 \pm 15.26$, which represents an increase of 9.63 (Table 3). Accordingly, in the coordination tests, children achieved almost one level higher results. After physiotherapy sessions, the children's coordination demonstrated an improvement by $23.36 \%$ (Table 3 ).

The first Eurofit test was Shuttle run 10 x 5m. Before PS, the total estimated average score for all children was $671.29 \pm 308.74$. After PS application, the mean score changed to $582.81 \pm 263.36$. The children's running speed and agility demonstrated a statistically significant increase. The children performed the task by $13.18 \%$ faster (Table 3 ).

The second Eurofit test was Standing Broad Jump. Mean scores for all children before and after the application of a PS program are shown in Table 3. The mean test results showed an increase of about
Table 3. The obtained testing results before and after PS program

Note. Eurofit ${ }^{1}-$ Shuttle run $10 \times 5$ m.; Eurofit ${ }^{2}$ - Standing Broad Jump.

\begin{tabular}{|l|c|c|c|c|}
\hline Tests & Before & After & Difference & Efficiency (\%) \\
\hline Modified Berg balance scale & 36.91 & 46.91 & 10 & 21.23 \\
\hline Coordination sample & 31.55 & 41.18 & 9.63 & 23.36 \\
\hline Eurofit $^{1}$ & 671.29 & 582.81 & 88.48 & 13.18 \\
\hline Eurofit $^{2}$ & 22 & 35 & 13 & 37.14 \\
\hline
\end{tabular}


22 up to 35 after PS. It indicates that the children's explosive leg strength statistically a significantly increased by 13 .

\section{DISCUSSION AND CONCLUSIONS}

The key challenges in working with children with ASD are to reduce the signs of autism and remove exclusion from the society, to increase functional independence, to improve the quality of life, to be included in public life. The early training should be a very important treatment strategy (Zhang et al., 2019). Therefore, looking for methods, ways, technological solutions which could solve such tasks must be a matter for everyone and especially for the governments. This paper has presented the investigation related with individual PS application applied for kindergarten children. The obtained results have indicated that the individual physiotherapy sessions are some of the ways to deal with the challenges faced by the autists. The investigation results have shown that the physiotherapy sessions are an effective tool for the children with ASD to improve physical condition and communications skills and have important benefits for the physical and psychological development. Rehabilitation training significantly improves the core symptoms and cognitive function in children with ASD.

During the investigation process, the three main aspects were observed and could be named:

The improving physical activity. The physical activity has improved the metabolic health, autistic behaviours, and the quality of life (Toscano, Carvalho, \& Ferreira, 2018). It also assists in attenuating the overweight and the obesity prevalence. Moreover, the physical activity has been revealed to be very important for children with ASD practicing various exercises (Sorensen \& Zarrett, 2014). Particularly the special and individual programs based on the physical capacity and status of each child is noted to be of a great help to reduce the risk to get injured. This allows ADS children to spend more time with other children and reduce the risk of injury at the same time. They also have more functional independence and can be included in the public life. According to ColomboDougovito and Reeve, (2017) and MacDonald et al. (2013), the motor skill and the social communication skill are interconnected. Therefore, the PS is named as one of the ways which can improve social and communication skills, increase self-esteem, functional independence, and improve the quality of life.

The evaluation of the abilities to do physical exercises in a group, at home or in individual sessions with a specialist. The difference in communication, ability and listening skills between children are set during the first test time. It has influenced the children's understanding how to practice the exercises and the further activities depending on it. Some of them quickly understood how to do one or other exercise, some others did not want to listen or to do anything because they preferred to stay in their individually world. Therefore, at the first stage of the testing procedure it is possible to determine the children's capabilities where they can do physical exercises in a group or at home, or if they needed individual sessions with specialist. However, according to the investigation carried out, it is recommended to have several individual sessions for every child. During the investigation time it was observed that some of children wanted to do exercises even though there was a lack of understanding. Therefore, it is needed to repeat or to show how to do exercises several times. After that, these children could be placed in children's groups and/or to do exercises at home with parents. At first parents must learn the exercises with a specialist so that children could do the exercises correctly.

However, there are children with ASD who lack understanding, listening, and ability skills. Therefore, such children are recommended to do exercises together with a specialist and for a longer time. Towards the end of the investigation it was observed that children's understanding, listening, and ability skills improved and they could do exercises faster and more precisely.

As Geslak (2017) states, exercising for many people, especially children with autism, is a problem because of a lack of information about exercises. Therefore, it is a great need to create a physiotherapy methodology that would allow having physical activity not only with a specialist but also at home with parents.

Compliance with Ethical Standards. All procedures performed in studies were in accordance with the ethical standards of the institutional and/ or national research committee and with the 1964 Declaration of Helsinki and its later amendments or comparable ethical standards. Informed Consent was obtained from all participants included in the study. The authors declare no conflict of interest. 


\section{REFERENCES}

American Psychiatric Association. (2014). Desk reference to the diagnostic criteria from DSM-5®. American Psychiatric Pub.

Autism Spectrum Disorders in the European Union (ASDEU). (2018). Call for tender, No. SANCO/2014/ C2/035. Retrieved from http://asdeu.eu/

Boat, T. F., \& Wu, J. T. (2015). Mental Disorders and Disabilities Among Low-Income Children. National Academies of Sciences, Engineering, and Medicine. https://doi.org/10.17226/21780

Caro, K., Tentori, M., Martinez-Garcia, A. I., \& Alvelais, M. (2017). Using the FroggyBobby exergame to support eye-body coordination development of children with severe autism. International Journal of Human Computer Studies, 105, 12-27. https://doi.org/10.1016/j. ijhes.2017.03.005

Carson, V., Ridgers, N. D., Howard, B. J., Winkler, E. A., Healy, G. N., Owen, N., ... \& Salmon, J. (2013). Lightintensity physical activity and cardiometabolic biomarkers in US adolescents. PloS One, 8(8), 1-7. https://doi. org/10.1371/journal.pone.0071417

CDC - Centers for Disease Control and Prevention. (2019). Data \& Statistics on Autism Spectrum Disorder CDC. CDC Government.

Colombo-Dougovito, A. M., \& Reeve, R. E. (2017). Exploring the Interaction of Motor and Social Skills With Autism Severity Using the SFARI Dataset. Perceptual and Motor Skills, 124(2), 413-424. https://doi. org/10.1177/0031512516689198

Connolly, A., Fielding, J., Papadopoulos, N., McGinley, J., Murphy, A., \& Rinehart, N. J. (2019). Factors associated with accidental injuries in children with ADHDCombined Type: More than a motor problem? Journal of Attention Disorders, 23(11), 1320-1330. https://doi. org/10.1177/1087054716633857

Cuffaro, M. A. (2011). Fine motor skills. In Encyclopedia of Child Behavior and Development. P. 657.

Curtin, C., Jojic, M., \& Bandini, L. G. (2014). Obesity in children with autism spectrum disorder. Harvard Review of Psychiatry, 22(2), 93-103. https://doi.org/10.1097/ HRP.0000000000000031

David, M. M., Babineau, B. A., \& Wall, D. P. (2016). Can we accelerate autism discoveries through crowdsourcing? Research in Autism Spectrum Disorders, 32, 80-83. https://doi.org/10.1016/j.rasd.2016.09.001

De Rubeis, S., He, X., Goldberg, A. P., Poultney, C. S., Samocha, K., Cicek, A. E., ... \& Singh, T. (2014). Synaptic, transcriptional and chromatin genes disrupted in autism. Nature, 515(7526), 209-215.5. https://doi. org/10.1038/nature 13772

Egan, A. M., Dreyer, M. L., Odar, C. C., Beckwith, M., \& Garrison, C. B. (2013). Obesity in young children with autism spectrum disorders: Prevalence and associated factors. Childhood Obesity, 9(2), 125-131. https://doi. org/10.1089/chi.2012.0028

Fujiwara, T., Morisaki, N., Honda, Y., Sampei, M., \& Tani, Y. (2016). Chemicals, nutrition, and autism spectrum disorder: A mini-review. Frontiers in Neuroscience, 10(174), 1-7. https://doi.org/10.3389/fnins.2016.00174

Gale, C. M., Eikeseth, S., \& Klintwall, L. (2019). Children with Autism show Atypical Preference for Non-social Stimuli. Scientific Reports, 9(10355), 1-10. https://doi. org/10.1038/s41598-019-46705-8

Gan, S. M., Tung, L. C., Tang, Y. H., \& Wang, C. H. (2008). Psychometric properties of functional balance assessment in children with cerebral palsy. Neurorehabilitation and Neural Repair, 22(6), 745-753. https://doi. org/10.1177/1545968308316474

Geslak, D. S. (2017). Challenging Autism with Exercise: An Opportunity Worth Stretching for. ACSM's Health and Fitness Journal, 21(2), 19-24. https://doi.org/10.1249/ FIT.0000000000000280

Giannopulu, I., \& Pradel, G. (2010). Multimodal interactions in free game play of children with autism and a mobile toy robot. NeuroRehabilitation, 27(4), 305-311. https://doi.org/10.3233/NRE-2010-0613

Gregor, S., Bruni, N., Grkinic, P., Schwartz, L., McDonald, A., Thille, P., ... \& Jachyra, P. (2018). Parents' perspectives of physical activity participation among Canadian adolescents with Autism Spectrum Disorder. Research in Autism Spectrum Disorders, 48, 53-62. https://doi.org/10.1016/j.rasd.2018.01.007

Healy, S., Aigner, C. J., \& Haegele, J. A. (2018). Prevalence of overweight and obesity among US youth with autism spectrum disorder. Autism, 23(4), 1046-1050. https://doi. org/10.1177/1362361318791817

Keogh, S., Bridle, C., Siriwardena, N. A., Nadkarni, A., Laparidou, D., Durrant, S. J., ... \& Curtis, F. (2019). Effectiveness of non-pharmacological interventions for insomnia in children with Autism Spectrum Disorder: A systematic review and meta-analysis. PloS one, 14(8), 1-13. https://doi.org/10.1371/journal.pone.0221428

Kogan, M. D., Vladutiu, C. J., Schieve, L. A., Ghandour, R. M., Blumberg, S. J., Zablotsky, B., ... \& Lu, M. C. (2018). The prevalence of parent-reported autism spectrum disorder among US children. Pediatrics, 142(6), 1-11. https://doi.org/10.1542/peds.2017-4161

Latorre Román, P. Á., López, D. M., Sánchez, M. F., Sánchez, J. S., Coronas, F. M., \& García-Pinillos, F. (2015). Test-retest reliability of a field-based physical fitness assessment for children aged 3-6 years. Nutricion Hospitalaria, 32(4), 1683-1688. https://doi.org/10.3305/ nh.2015.32.4.9486

Lim, Y. H., Lee, H. C., Falkmer, T., Allison, G. T., Tan, T., Lee, W. L., \& Morris, S. L. (2019). Effect of Visual Information on Postural Control in Adults with Autism Spectrum Disorder. Journal of Autism and Developmental Disorders, 49, 4731-4739. https://doi.org/10.1007/ s10803-018-3634-6

MacDonald, M., Esposito, P., \& Ulrich, D. (2011). The physical activity patterns of children with autism. $B M C$ Research Notes, 4(422), 1-5.https://doi.org/10.1186/17560500-4-422 
MacDonald, M., Lord, C., \& Ulrich, D. A. (2013). The relationship of motor skills and social communicative skills in school-aged children with autism spectrum disorder. Adapted Physical Activity Quarterly, 30(3), 271-282. https://doi.org/10.1123/apaq.30.3.271

Masi, A., DeMayo, M. M., Glozier, N., \& Guastella, A. J. (2017). An Overview of Autism Spectrum Disorder, Heterogeneity and Treatment Options. Neuroscience Bulletin, 33, 183-193. https://doi.org/10.1007/s12264017-0100-y

McCleery, J. P., Elliott, N. A., Sampanis, D. S., \& Stefanidou, C. A. (2013). Motor development and motor resonance difficulties in autism: Relevance to early intervention for language and communication skills. Frontiers in Integrative Neuroscience, 7(30), 1-20. https://doi.org/10.3389/fnint.2013.00030

Memari, A. H., Ghanouni, P., Gharibzadeh, S., Eghlidi, J., Ziaee, V., \& Moshayedi, P. (2013). Postural sway patterns in children with autism spectrum disorder compared with typically developing children. Research in Autism Spectrum Disorders, 7(2), 325-332. https://doi. org/10.1016/j.rasd.2012.09.010

Metwaly, D. (2015). Impact of hydrogymnastics on motor abilities and social behavior among preschool children. Science, Movement and Health, 4(2), 321-328.

Miller, H. L., Caçola, P. M., Sherrod, G. M., Patterson, R. M., \& Bugnariu, N. L. (2019). Children with Autism spectrum disorder, developmental coordination disorder, and typical development differ in characteristics of dynamic postural control: A preliminary study. Gait and Posture, 67, 9-11. https://doi.org/10.1016/j. gaitpost.2018.08.038

Modabbernia, A., Velthorst, E., \& Reichenberg, A. (2017). Environmental risk factors for autism: An evidencebased review of systematic reviews and meta-analyses. Molecular Autism, 8(13), 1-16. https://doi.org/10.1186/ s13229-017-0121-4

Mohajer, B., Masoudi, M., Ashrafi, A., Mohammadi, E., Ershadi, A. S. B., Aarabi, M. H., \& Uban, K. A. (2019). Structural white matter alterations in male adults with high functioning autism spectrum disorder and concurrent depressive symptoms: Adiffusion tensor imaging study. Journal of Affective Disorders, 259, 40-46. https:// doi.org/10.1016/j.jad.2019.08.010

Nevison, C. D. (2014). A comparison of temporal trends in United States autism prevalence to trends in suspected environmental factors. Environmental Health: A Global Access Science Source, 13(73), 1-16. https://doi. org/10.1186/1476-069X-13-73

Nor, N. K., Ghozali, A. H., \& Ismail, J. (2019). Prevalence of overweight and obesity among children and adolescents with autism spectrum disorder and associated risk factors. Frontiers in Pediatrics, 7(38), 1-0. https://doi. org/10.3389/fped.2019.00038

O’Sullivan, S. B., Schmitz, T. J., \& Fulk, G. (2019). Physical rehabilitation. FA Davis.

Robinson, E. B., St Pourcain, B., Anttila, V., Kosmicki, J. A., Bulik-Sullivan, B., Grove, J., ... \&
Martin, J. (2016). Genetic risk for autism spectrum disorders and neuropsychiatric variation in the general population. Nature Genetics, 48(5), 552-555. https://doi. org/10.1038/ng.3529

Sibley, K. M., Beauchamp, M. K., Van Ooteghem, K., Paterson, M., \& Wittmeier, K. D. (2017). Components of Standing postural control evaluated in pediatric balance measures: A scoping review. Archives of Physical Medicine and Rehabilitation, 98(10), 2066-2078. https:// doi.org/10.1016/j.apmr.2017.02.032

Sorensen, C., \& Zarrett, N. (2014). Benefits of physical activity for adolescents with autism spectrum disorders: A comprehensive review. Review Journal of Autism and Developmental Disorders, 1, 344-353. https://doi. org/10.1007/s40489-014-0027-4

Stein, J. L., Parikshak, N. N., \& Geschwind, D. H. (2013). Rare inherited variation in autism: Beginning to see the forest and a few trees. Neuron, 485(7397), 237-241. https://doi.org/10.1016/j.neuron.2013.01.010

Stevenson, J. L., Lindley, C. E., \& Murlo, N. (2017). Retrospectively assessed early motor and current pragmatic language skills in autistic and neurotypical children. Perceptual and Motor Skills, 124(4), 777-794. https://doi.org/10.1177/0031512517710379

Toscano, C. V.A., Carvalho, H. M., \& Ferreira, J. P. (2018). Exercise Effects for Children With Autism Spectrum Disorder: Metabolic Health, Autistic Traits, and Quality of Life. Perceptual and Motor Skills, 125(1), 126-146. https://doi.org/10.1177/0031512517743823

van der Zee, E., \& Derksen, J. J. L. (2020). Reconsidering Empathy Deficits in Children and Adolescents with Autism. Journal of Developmental and Physical Disabilities, 32, 23-39. https://doi.org/10.1007/s10882-019-09669-1

Williams, S. M., Eleftheriadou, A., Alam, U., Cuthbertson, D. J., \& Wilding, J. P. H. (2019). Correction to cardiac autonomic neuropathy in obesity, metabolic syndrome and prediabetes: A narrative review. Diabetes Therapy, 10(6), 1995-2021. https://doi.org/10.1007/ s13300-019-00705-z

World Health Organization. (2018). Autism spectrum disorders Fact Sheet. Geneva, Switzerland: World Health Organization. Retrieved from https://www.who.int/newsroom/fact-sheets/detail/autism-spectrum-disorders.

Ye, B. S., Leung, A. O. W., \& Wong, M. H. (2017). The association of environmental toxicants and autism spectrum disorders in children. Environmental Pollution, 227, 234 242. https://doi.org/10.1016/j.envpol.2017.04.039

Zerbo, O., Qian, Y., Ray, T., Sidney, S., Rich, S., Massolo, M., \& Croen, L. A. (2019). Health Care Service Utilization and Cost Among Adults with Autism Spectrum Disorders in a U.S. Integrated Health Care System. Autism in Adulthood, 1(1), 27-36. https://doi.org/10.1089/ aut.2018.0004

Zhang, L., Liu, Y., Zhou, Z., Wei, Y., Wang, J., Yang, J., ... \& Sun, Y. (2019). A follow-up study on the long-term effects of rehabilitation in children with autism spectrum disorders. NeuroRehabilitation, 44(1), 1-7. https://doi. org/10.3233/NRE-182502 